\title{
ПРОЛОНГАЦИЯ БЕРЕМЕННОСТИ ДО 14 ДНЕЙ И БОЛЕЕ 14 ПРИ ПРЕЖДЕВРЕМЕННОМ ИЗЛИТИИ ОКОЛОПЛОДНЫХ ВОД
}

\section{PROLONGATION OF PREGNANCY TO 14 \\ DAYS AND $\geq 14$.IN CASE OF PREMATURE DISCHARGE OF AMNIOTIC FLUID}

\section{N. Shubitidze \\ T. Gustovarov \\ I. Taboridze}

Summary. Prematurity is the main cause of perinatal morbidity and mortality in economically developed countries. In about every third case, the development of labor during premature pregnancy is provoked by premature rupture of the membranes and partial or complete rupture of amniotic fluid [1]. Objective: To determine the factors of prolongation of pregnancy with premature discharge of amniotic fluid. Materials and methods: We studied the clinical and laboratory features in 196 patients with prenatal amniotic fluid outflow from the contingent of the clinics Gagua and Pineo, who carried out a pregnancy extension in 2016-2018 with gestational periods of 22-34 weeks. The selection criteria for prolonging the pregnancy of PIU patients was the absence of clinical and laboratory signs of an ascending infection, as well as signs of hypoxia and intrauterine growth retardation. Obstetric management of pregnant women with PRPO consisted in the maximum prolongation of pregnancy in the absence of contraindications. The following were determined: Socio-biological factors of the mother, Obstetric and gynecological history: complicated course of the previous pregnancy, Extragenital diseases, Complications of pregnancy, Fetal status, Ultrasound parameters, laboratory tests - general analysis of blood and urine, bacterioscopy and smear bacteriology. Results: The gestational age during amniotic fluid effusion ranged from 22 to 34 weeks, an average of $29.1+3.0$, Among 196 pregnant women with untimely discharge of amniotic fluid, prolongation of pregnancy was successful in 138 cases (70.40\%). Average prolongation of 31.2 (0-179) days prolongation of 14 days or more was observed in 120 (61.22\%) cases (group I) and prolongation failed or continued for less than 14 days in 76 (38.78\%) cases (group II). In the prolongation group $<14$ days. Compared to $\geq 14$, the age of the mother was significantly higher, respectively $28.84+5.73$ and $26.92+5.91(p=0.0249)$, and the male sex prevailed - respectively $54(71.05 \%)$ and $48(40.00 \%)$, $p<0.0001$. Amniotic fluid (I) - respectively $1.13+0.93$ and $2.42+$ $1.13(\mathrm{p}<0.0001)$, Cervical length $(\mathrm{mm})$ - respectively $24.39+4.63$ and $29.45+6.84(p<0.0001)$, Cervical dilatation $(\mathrm{mm})$ - respectively $3.45+2.58$ and $1.95+2.68(p=0.0001)$. Conclusions: 1 . Prolongation of pregnancy depends on socio-biological factors, obstetric and gynecological history and pregnancy factors. 2. Prolongation is promoted by a high average rate of amniotic fluid and cervical length and a low rate of cervical dilatation.

\author{
Шубитидзе Нана Георгиевна \\ Смоленский Государственный Медицинский \\ Университет \\ nanashubitidze3@gmail.com \\ Густоварова Татьяна Алексеевна \\ Д.м.н., профессор, Смоленский Государственный \\ Медицинский Университет \\ таборидзе Иамзе Ираклиевна \\ Академический доктор, профессор. Университет \\ Давида Агмашенебели Грузии, Тбилиси, Грузия \\ iataboridze@yahoo.com
}

Аннотачия. Преждевременный разрыв плодных оболочек (PROM) осложняет примерно 10\% беременностей и является причиной примерно четверти преждевременных родов. Цель исследования: Определить факторов пролонгации беременности при преждевременной излитии околоплодных вод. Материалы и методы: Изучили клинико-лабораторные особенности у 196 пациенток с дородовым излитием околоплодных вод из контингента клиники Д. Гагуа и Медицинская экосистема Пинео, которым в 2016-2018гг. проведена пролонгация беременности при сроках гестации 22-34 недели. Критериями отбора для пролонгирования беременности пациенток с ПИОВ явилось отсутствие клинических и лабораторных признаков восходящей инфекции и признаков гипоксии и задержки внутриутробного развития плода. Акушерская тактика ведения беременных с ПРПО заключалась в максимальном пролонгировании беременности при отсутствии противопоказаний. Определяли: Социально-биологические факторы матери, акушерско-гинекологический анамнез: осложненное течение предыдущей беременности, экстрагениталъные заболевания, осложнения беременности, состояние плода, параметры узи, лабораторные исследования - общий анализ крови и мочи, бактериоскопия и бактериология мазка. Результаты и их обсуждения: Срок беременности во время излития околоплодных вод составил от 22 до 34 недель, в среднем 29.1+3.0. Среди 196 беременных с несвоевременной излитием околоплодных вод, пролонгация беременности удалось в 138 случае (70.40\%). (реднее пролонгирование 31.2 (0-179) дней. Пролонгация на 14 и более суток наблюдалось в 120 (61.22\%) случаях (I группа), и пролонгация не удалась или продолжалась менее чем 14 суток в 76 (38.78\%) случаях (II группа). В группе пролонгации <14 д. По сравнению $\mathrm{c} \geq 14$ значимо выше возраст матери - соответственно $28.84+5.73$ и $26.92+5.91(\mathrm{p}=0.0249)$ и превалировал мужской пол ребенка - соответственно 54(71.05\%) и 48(40.00\%), p $<0.0001$. Околоплодные воды(л) - соответственно $1.13+0.93$ и 2.42+1.13 ( $<<0.0001)$, Длина шейки матки(мм) - соответственно 24.39+4.63 и 29.45+6.84 ( $<<0.0001)$, Дилатация шейки матки(мм) - соответственно $3.45+2.58$ и $1.95+2.68(p=0.0001)$. Выводы: 1. Пролонгация беременности зависит от социально биологических факторов, акушерско-гинекологического анамнеза и факторов беременности. 2. Пролонгацию способствует высокий средний показатель количества околоплодных вод и длины шейки матки и низкий показатель дилатации шейки матки. 
Keywords: pregnancy prolongation, premature discharge of amniotic fluid.

\section{Актуа^ьность}

$\mathbf{H}$ едонашивание беременности - основная причина перинатальной заболеваемости и смертности в экономически развитых странах $[1,2,3]$. Преждевременный разрыв плодных оболочек (PROM) осложняет примерно 10\% беременностей и является причиной примерно четверти преждевременных родов [4].

После разрыва, преждевременные роды часто наступают на следующей неделе [5]. Однако латентный период коррелирует с гестационным возрастом, чем дольше гестационный возраст, тем больше латентный период между разрывом и родами [6,7].

40\% случаев излитие околоплодных вод связано с преждевременными родами и является причиной перинатальных потерь[8].

При недоношенной беременности, осложнившейся преждевременным излитием вод, целесообразно использование консервативно-выжидательной тактики ведения $[9,10]$.

Целью выжидательной тактики - пролонгировать беременность до сроков, при которых достигаются все признаки морфофункциональной зрелости плода. Изза опасности осложнений, которым подвергаются плод и мать при наличии внутри-амниотической инфекции, рекомендуется постоянно исключать противопоказания к выжидательному ведению беременности. Абсолютные противопоказания к пролонгированию беременности включают хориоамнионит, страдание плода и наличие активной родовой деятельности.

\section{Цель исследования}

Определить факторы пролонгации беременности при преждевременной излитии околоплодных вод.

\section{Материалы \\ и мето $\Delta$ ы}

Изучили клинико-лабораторные особенности у 196 пациенток с дородовым излитием околоплодных вод из контингента клиники Гагуа и Пинео, которым в 20162018 гг. проведено пролонгация беременности при сроках гестации 22-34 недели.
Ключевые слова: пролонгация беременности, преждевременное излитие околоплодных вод.

Критерии включения: пролонгирования беременности пациенток с ПИОВ явилось отсутствие клинических и лабораторных признаков восходящей инфекции,

Критерий исключения: лихорадка, тахикардия, лейкоцитоз, гипоксия задержка внутриутробного развития плода.

Акушерская тактика ведения беременных с ПРПО заключалась в максимальном пролонгировании беременности. При отсутствии противопоказаний, проводили токолиз, антибактериальную терапию и профилактики респираторного дистресс синдрома (РДС) плода. Женщин, которые являлись клинически стабильными после 48 ч наблюдения, лечили дома.

Мониторинг состояния беременных включал оценку соматического и акушерского статусов, гемодинамических параметров, 3-часовой термометрии, ежедневного клинического анализа крови, бактериологического анализа, отделяемого из цервикального канала.

С помощью ультразвуковой фетометрии ежедневно оценивали индекс амниотической жидкости на ультразвуковом аппарате GEVolusonE8, UltrasoundMachine nederland, провоил ежедневную кардиотокографию (КТГ) аппаратом SonicaidTeamCape, а также допплерографического исследования кровотока в артерии пуповины, аорте плода, маточных артериях. Оценка клеточного состава крови проведена с помощью гематологического анализатора MEK 7300 NihonKohden -Japan. Биохимические анализы - BTS350 BioSystemsSpain. придерживались выжидательной тактики ведения беременности с профилактикой возможного развития инфекционно-воспалительных осложнений.

Данные были собраны интервьюером под управлением структурированной анкеты.

Определяли: социально-биологические факторы матери, акушерско-гинекологический анамнез: осложненное течение предыдущей беременности, экстрагениталъные заболевания, осложнения беременности, состояние плода, лабораторные исследования -общий анализ крови, узи, бактериоскопия и бактериология мазка, общий анализ мочи.

Диагностика состояния плода включала проведение ультразвуковой фетометрии с ежедневной оценкой ин- 


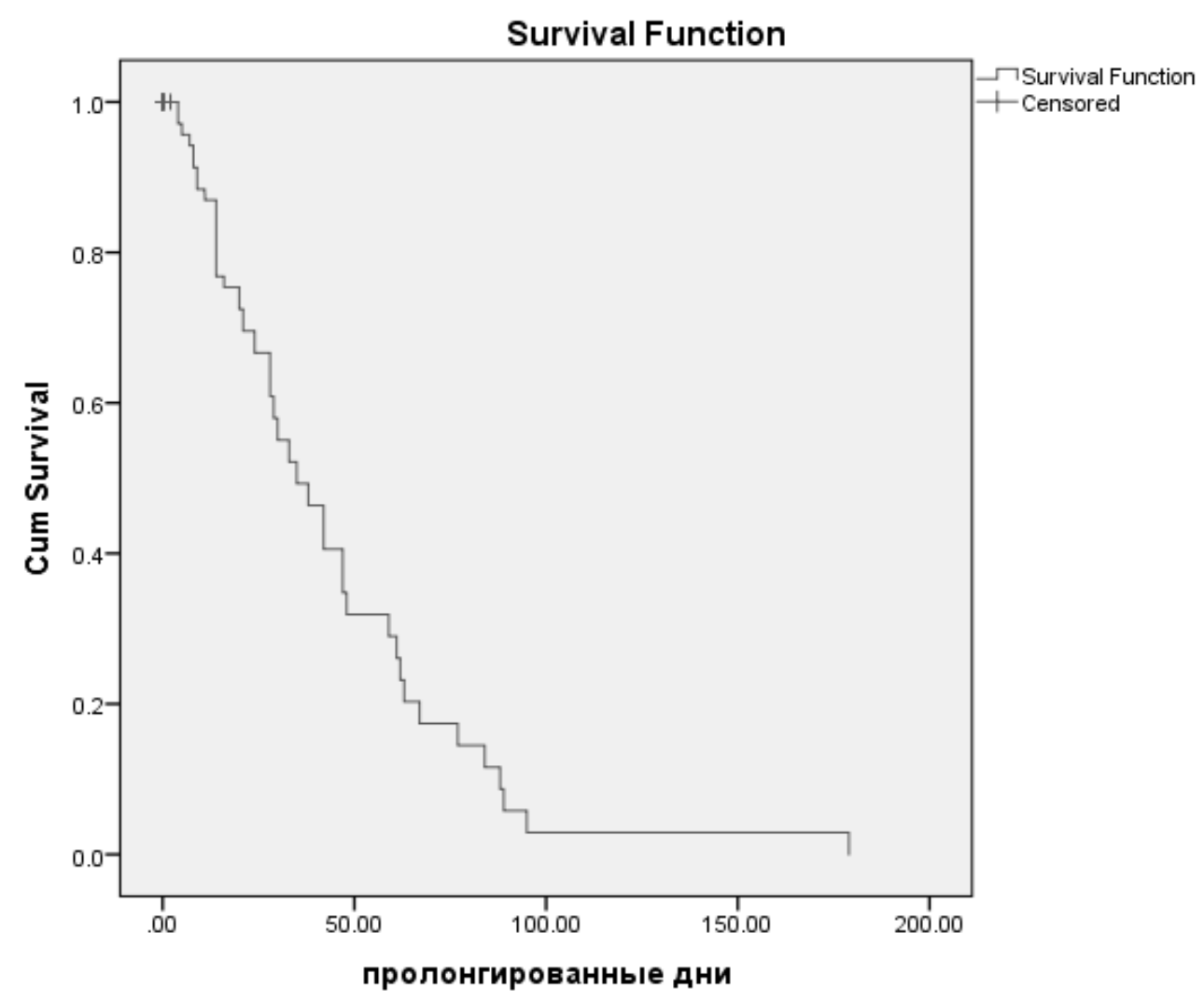

Рис. 1

декса амниотической жидкости на ультразвуковом аппарате Volusone8 Expert, ежедневной кардиотокографии (КТГ) аппаратом SonicaidTeamCape, а также допплерографического исследования кровотока в артерии пуповины, аорте плода, маточных артериях. Оценка клеточного состава крови проведена с помощью гематологического анализатораMEK 7300 NihonKohden -Japan.

\section{Статистический анализ}

Материал был разработан с использованием вариационной статистики: вычисляли среднее, среднеквадратическое отклонение, сравнение количественных характеристик проводили с помощью критерии Стьюдента. Для качественных показателей различия между группами мы оценили, используя критерий $\mathrm{F}$ (Фишера). Статистический анализ проводился с помощью программного пакета SPSS23.

\section{Результаты}

Срок беременности во время излития околоплодных вод составил от 22 до 34 недель, в среднем 29.1+3.0.
Среди 196 беременных с несвоевременной излитием околоплодных вод, пролонгация беременности удалось в 138 случаях (70.40\%). Среднее пролонгирование 31.2 (0-179) дней.

На диаграмме представлена функция выживания, которая показывает пролонгирование беременности после разрыва околоплодных оболочек.

При дородовой излитии околоплодных вод пролонгация на 14 и более суток наблюдалось в 120(61.22\%) случаях (І группа) и пролонгация не удалась или продолжалась менее чем 14 суток в 76 (38.78\%) случаях (II группа).

Срок беременности в обеих группах были сопоставимы и значимо не различались соответственно $29.16+3.04$ и $29.05+2.95(t=0.24, p=0.8069)$.

В группе пролонгации <14 д. По сравнению с $\geq 14$ значимо выше возраст матери - соответственно 28.84+5.73 и 26.92+5.91 ( $\mathrm{t}=2.26, \mathrm{p}=0.0249)$ и превалировал мужской пол ребенка - соответственно 54(71.05\%) и 48 (40.00\%), $F=19.59, \mathrm{p}<0.0001$. 


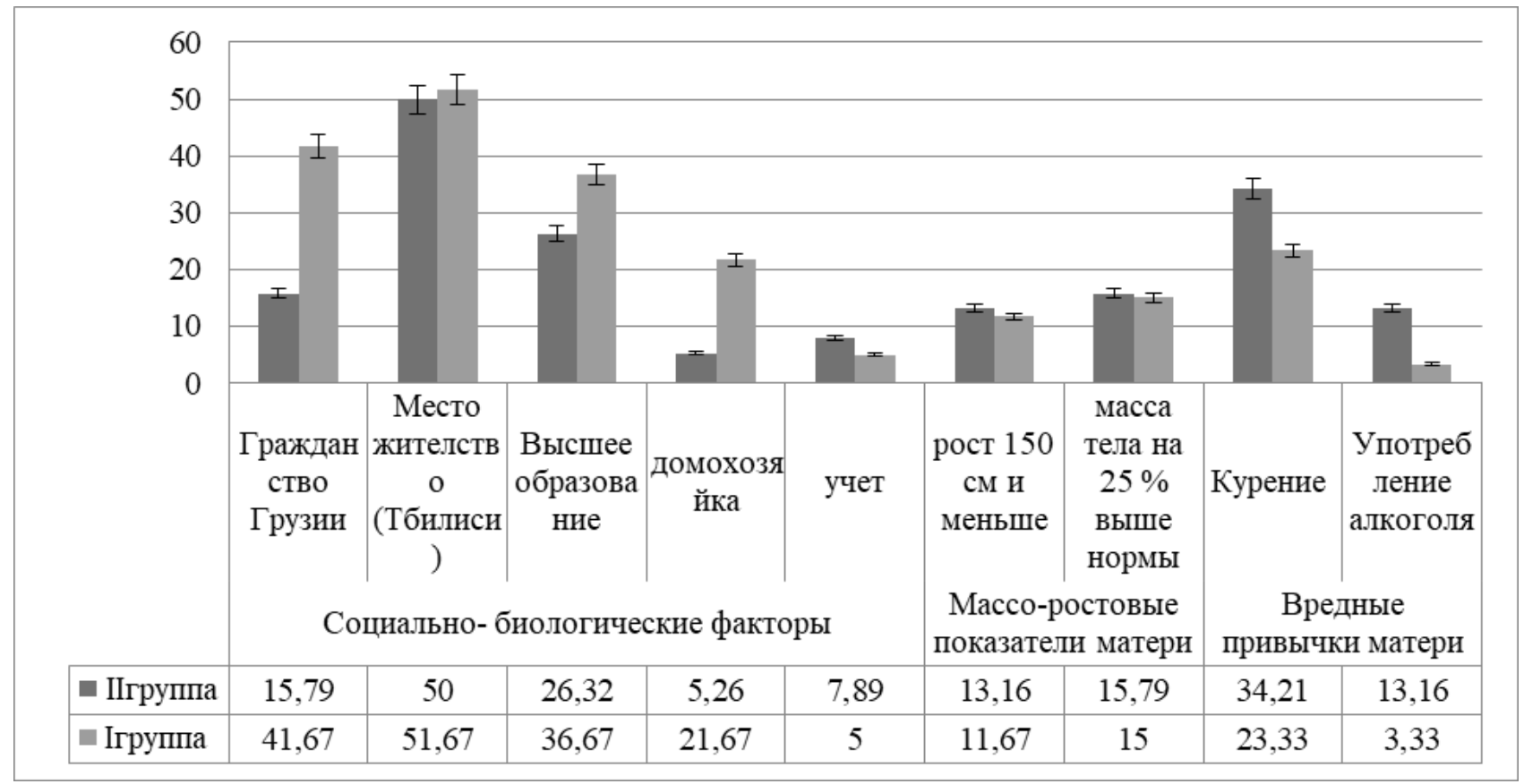

Диаграмма 1. Социально-биологические факторы и вредные привычки матери

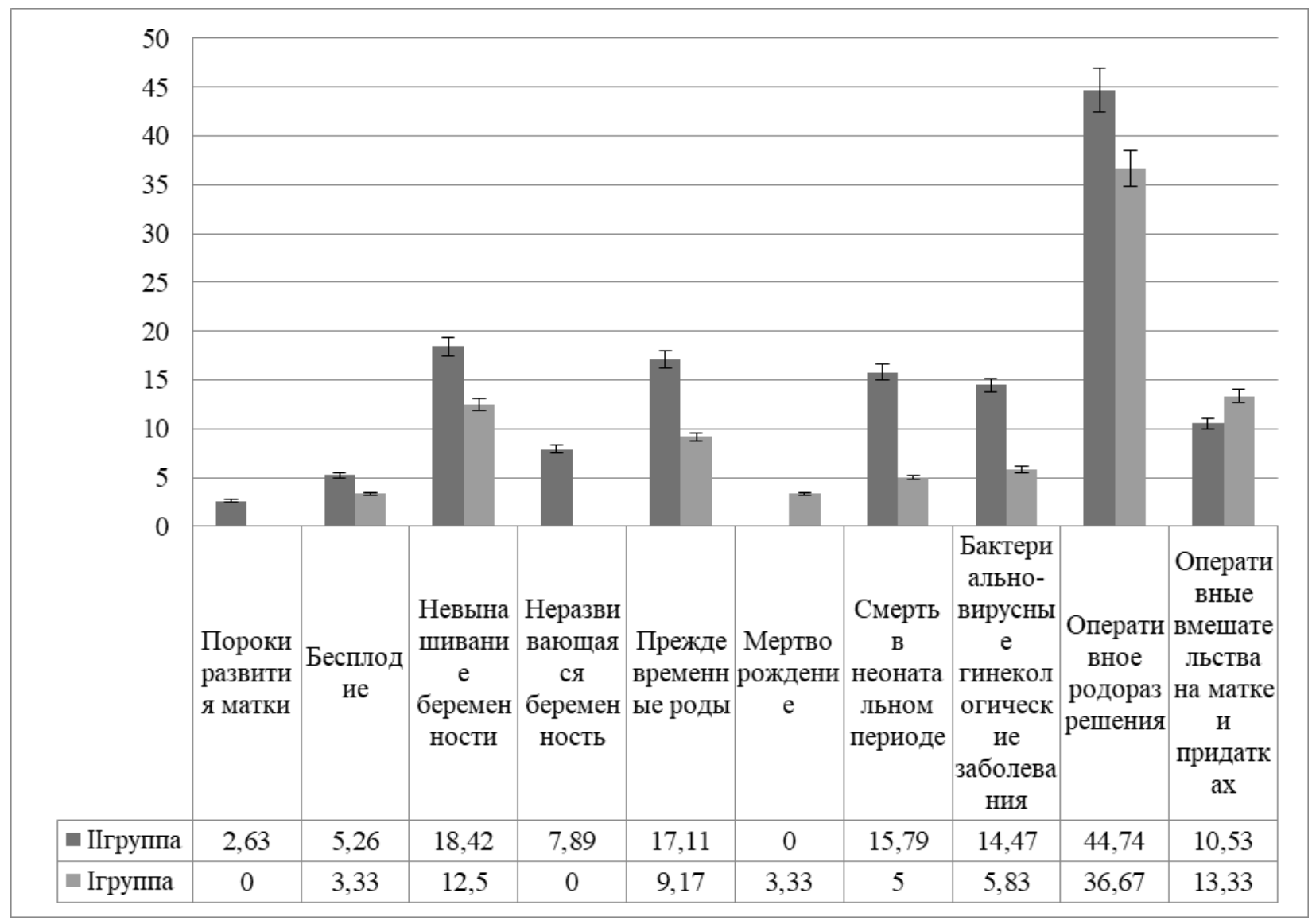

Диаграмма 2. Акушерско- гинекологический анамнез среди беременных 
Таблица 1.

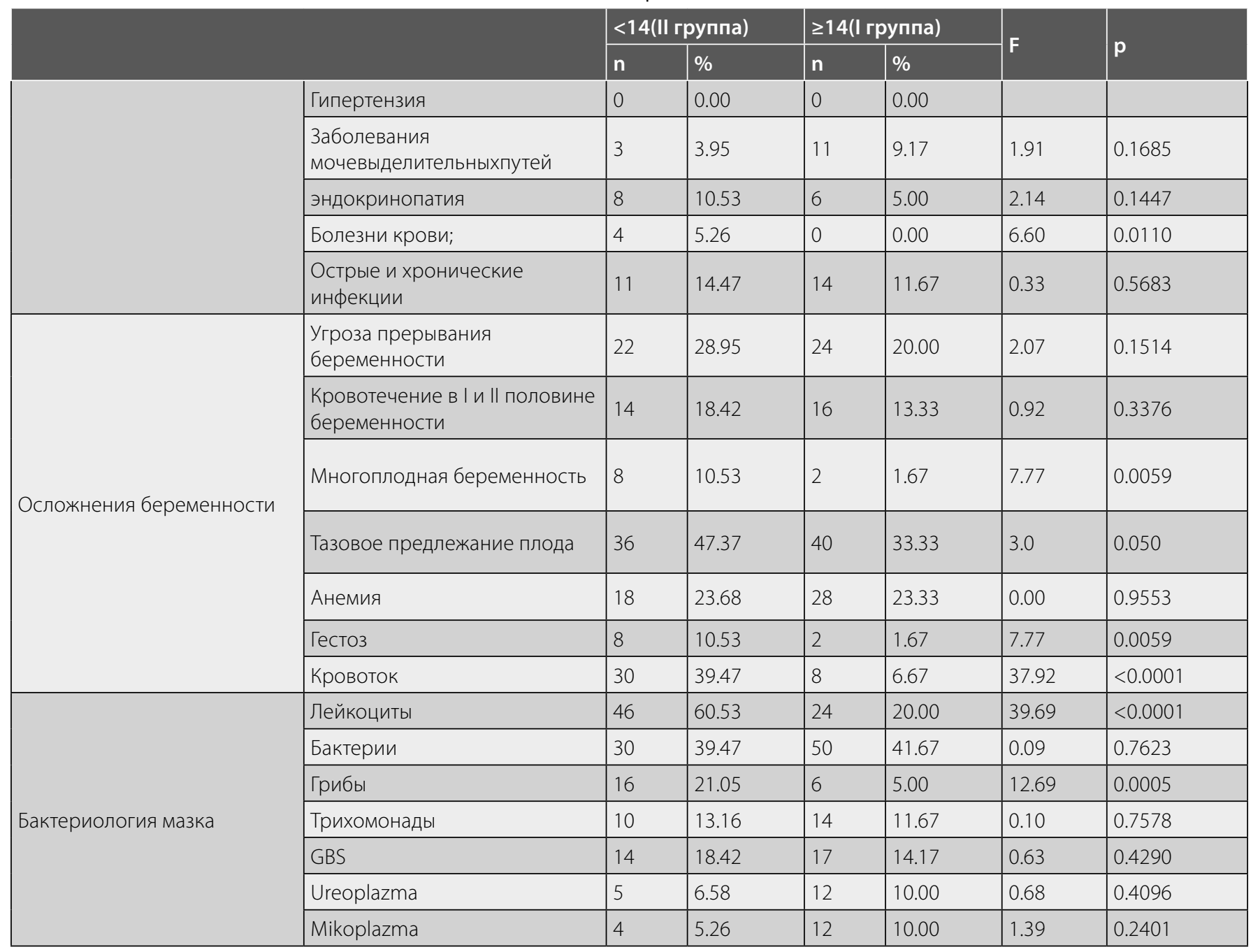

Таблица 2.

\begin{tabular}{|c|c|c|c|c|c|}
\hline & & & $>13$ & & Tatal \\
\hline & & & 1 & II & Iotai \\
\hline & 1 & $n$ & 32 & 54 & 86 \\
\hline & 1 & $\%$ & $42.1 \%$ & $45.0 \%$ & $43.9 \%$ \\
\hline & 2 & $n$ & 18 & 38 & 56 \\
\hline & $L^{2}$ & $\%$ & $23.7 \%$ & $31.7 \%$ & $28.6 \%$ \\
\hline 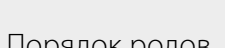 & 3 & $n$ & 18 & 22 & 40 \\
\hline 1 & S & $\%$ & $23.7 \%$ & $18.3 \%$ & $20.4 \%$ \\
\hline & 1 & $n$ & 6 & 6 & 12 \\
\hline & $I^{4}$ & $\%$ & $7.9 \%$ & $5.0 \%$ & $6.1 \%$ \\
\hline & & $n$ & 2 & 0 & 2 \\
\hline & J & $\%$ & $2.6 \%$ & $0.0 \%$ & $1.0 \%$ \\
\hline Total & & $n$ & 76 & 120 & 196 \\
\hline 2 & & & 5.57 & & \\
\hline$p$ & & & 0.233 & & \\
\hline
\end{tabular}


Таблица 3. Ультрасонографические показатели при преждевременной излитии околоплодных вод

\begin{tabular}{|c|c|c|c|c|}
\hline & $\begin{array}{l}<14 \text { (II группа) } \\
\text { n=76 }\end{array}$ & $\begin{array}{l}\geq 14(\mathrm{I}) \text { группа } \\
\mathrm{n}=120\end{array}$ & \multirow[t]{2}{*}{ F или $t$} & \multirow[t]{2}{*}{ p } \\
\hline & M+SD или n(\%) & M+SD или n(\%) & & \\
\hline Толщина плаценты & $31.42+3.30$ & $30.38+4.80$ & 1.65 & 0.1000 \\
\hline Степень зрелости плаценты & $1.34+0.78$ & $1.33+0.81$ & 0.08 & 0.9397 \\
\hline Околоплодные воды(л) & $1.13+0.93$ & $2.42+1.13$ & -8.69 & $<0.0001$ \\
\hline Длина шейки матки(мм) & $24.39+4.63$ & $29.45+6.84$ & -5.67 & $<0.0001$ \\
\hline Дилатация шейки матки(мм) & $3.45+2.58$ & $1.95+2.68$ & 3.90 & 0.0001 \\
\hline Переднее прикрепление плаценты & $30(39.47)$ & $38(31.67)$ & 1.25 & 0.2655 \\
\hline Неоднородная структура плаценты & $42(55.26)$ & $68(56.67)$ & 0.03 & 0.8681 \\
\hline
\end{tabular}

Таблица 4.

\begin{tabular}{|c|c|c|c|c|}
\hline & $\begin{array}{l}<14 \text { (II группа) } \\
\text { n=76 }\end{array}$ & $\begin{array}{l}\geq 14(\mathrm{I}) \text { группа } \\
\mathrm{n}=120\end{array}$ & \multirow[t]{2}{*}{$t$} & \multirow[t]{2}{*}{$p$} \\
\hline & M+St.D & M+St.D & & \\
\hline Лейкоциты & $12.92+2.81$ & $12.48+3.28$ & 1.00 & 0.3189 \\
\hline Эритроциты & $3.56+0.33$ & $3.63+0.38$ & -1.50 & 0.1364 \\
\hline Гемоглобин & $10.51+1.20$ & $10.74+0.89$ & & 0.1555 \\
\hline Гематокрит & $32.57+3.31$ & $33.15+4.68$ & -1.00 & 0.3188 \\
\hline Тромбоциты & $226.05+52.10$ & $260.05+56.14$ & -4.32 & $<0.0001$ \\
\hline $\mathrm{COэ}$ & $53.68+15.97$ & $47.52+15.35$ & 2.67 & 0.0083 \\
\hline Палочкоядерные & $7.34+1.88$ & $6.42+2.04$ & 3.25 & 0.0014 \\
\hline Сегментоядерные & $73.13+7.47$ & $71.63+5.47$ & 1.51 & 0.1332 \\
\hline Эозинофилы & $1.34+0.48$ & $1.32+0.62$ & 0.32 & 0.7474 \\
\hline Лимфоциты & $11.21+3.95$ & $15.58+6.08$ & -5.57 & 0.0000 \\
\hline Моноциты & $5.39+2.07$ & $5.35+1.96$ & 0.15 & 0.8808 \\
\hline
\end{tabular}

Bo II группе по сравнении с первой группой значимо превышена частота таких факторов, как гражданство Грузии - $\mathrm{p}=0.0001$ и домохозяйка $-\mathrm{p}=0.0018$, а в первой - употребление алкоголя - $\mathrm{p}=0.0091$ и незначимо - частота курении.

На диаграмме 2 представлен акушерско-гинекологический анамнез среди беременных при пролонгации беременности при НИОВ. В обеих группах превалирует оперативное родоразрешение. Пороки развития матки и неразвивающаяся беременность наблюдались только во II группе.

Bo II группе по сравнении с I группой значимо превышена частота таких факторов в анамнезе, как-смерть

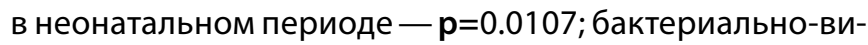
русные гинекологические заболевания - $\mathbf{p}=0.0415$;

В таблице1 представлена статистическая оценка предполагаемых факторов беременности в группах пролонгации на 14 и более дней (I группа) и <14 и без пролонгации беременности (II группа).
Статистическая оценка предполагаемых факторов беременности в группах пролонгации на 14 и более дней (I группа) и <14 и без пролонгации беременности (II группа).

В группе пролонгации <14дней, по сравнении с группой с пролонгации беременности на $\geq 14$ дней, значимо превышена частота таких факторов, как гестоз - $\mathrm{p}=0.0059$; болезни крови $-\mathrm{p}=0.0110$; многоплодная беременность; тазовое предлежание плода; кровоток; лейкоциты и грибы в мазке.

Вызывает интерес зависимость пролонгации от порядка беременности (таблица 2)

По порядке рождения, как и по значимой различия нулипарнорности (Перворождаемость) между группами значимой различии не наблюдалось.

В таблице 3 представлены ультрасонографические показатели в группах пролонгации и без пролонгации беременности 
В группе пролонгации $\geq 14$ дней отмечается значимо высокий средний показатель количества околоплодных вод и длины шейки матки и меньше - дилатация шейки матки, чем в группе без пролонгации. Значимой не оказалось различие по толщине, степени зрелости и структуре плаценты

Оценка лабораторных показателей представлены в таблице 4

B II группе значимо повышены средние показатели СОЭ и палочкоядерных неитрофилов, и понижены средние показатели лимфоцитов и тромбоцитов.

\section{ОбсужАение}

Двойная беременность и хориоамнионит являются факторами, существенно влияющими на латентный интервал [11]. По данным нашего исследования многоплодная беременность значимо низкой частотой встречается в группе пролонгации.

Обнаружено, что нулипарность связана с укорочением латентного периода $(p=0,012)$ и что пожилой возраст матери> 30 лет связан с продлением латентного периода ( $p=0,000)$ [10], что на нашем материале не подтверждается AFI и SDP в сочетании с TVCL интервала задержки от PPROM до доставки.

По данным литературы параметры, включающие индекс околоплодных вод (AFI) и трансвагинальная длина шейки матки (TVCL) могут быть полезными прогностическими параметрами пролонгации $[12,13]$. Параметры УЗИ также значительны по результатам нашей работы - длина шейки матки и объем околоплодных вод значимо меньше среди женщин без пролонгации, а дилатация - во второй группе. Отмечают, что пациенты с длиной шейки матки <25 мм будут рожать раньше [14]. На нашем материале, в группе пролонгации $\geq 14$ дней длина шейки матки составляет $29.45+6.84 \mathrm{Mм}$, а в группе $<14$ дней - 24.39+4.63мм. несостоятельность плодных оболочек формируется на фоне системных метаболических расстройств и изменений клеточного состава периферической крови[15] Среди лабораторных показателей значимыми оказались факторы, указывающие на воспалительный компонент.

Кроме вышесказанного, пролонгация беременности зависит как от факторов беременности, так и от акушерско-гинекологического анамнеза беременной, от вредных привычек и социального статуса, среди ультрасонографических характеристик информативными оказались параметры матки и объем околоплодных вод.

\section{Выво $\Delta$}

1. Пролонгация беременности зависит от социально биологических факторов, акушерско-гинекологического анамнеза и факторов беременности. 2. Пролонгацию способствует высокий средний показатель количества околоплодных вод и длины шейки матки и низкий показатель дилатации шейки матки.

\section{ЛИТЕРАТУРА}

1. Орлова В.С., Калашникова И.В., Набережнев Ю.И. Подходы к ведению недоношенной беременности при преждевременном излитии околоплодных вод // Научные ведомости БелГУ. Серия: Медицина. Фармация. 2010. № 16 (87). С. 13-22.

2. Pendse A. et al. Neonatal outcomes following previable prelabour rupture of membranes before 23 weeks of gestation-a retrospective cohort study //Journal of Neonatal-Perinatal Medicine. 2020. Preprint. C. 1-11.

3. Sim W.H. et al. Maternal and neonatal outcomes following expectant management of preterm prelabour rupture of membranes before viability //Journal of perinatal medicine. - 2017. - T. 45. № . 1. C. 29-44.

4. Mercer B.M. Premature rupture of the membranes //Protocols for High-Risk Pregnancies: An Evidence-Based Approach. - 2020. C. 461-474.

5. Panzer A. et al. Factors associated with previable delivery following second trimester rupture of membranes //American journal of perinatology. - 2019. T. 36. — № . 8. - C. 812 .

6. Baser E., Aydogan Kirmizi D., Ulubas Isik D., Ozdemirci S., Onat T., Serdar Yalvac E. \& Moraloglu Tekin, 0. (). The effects of latency period in PPROM cases managed expectantly. The Journal of Maternal-Fetal \& Neonatal Medicine, 2020, 33(13), 2274-2283.

7. Parrish M.M. et al. Does early artificial rupture of membranes speed labor in preterm inductions? //American journal of perinatology.— 2018. — T. 35.— № . 08.- - . 716-720.

8. Михайлов А.В. и др. Ведение беременности, осложненной преждевременным излитием околоплодных вод при недоношенной беременности //Акушерство и гинекология. - 2014. — № . 2.— С. 74-79.

9. Migliorelli F., Martin C., Martínez de Tejada B. Preterm prelabor rupture of membranes management in Switzerland: a national survey //The Journal of MaternalFetal \& Neonatal Medicine. - 2020. - C. 1-8.

10. Dagklis T. et al. Parameters affecting latency period in PPROM cases: a 10-year experience of a single institution //The Journal of Maternal-Fetal \& Neonatal Medicine. 2013. Vol. 26. № . 14. C. 1455-1458. 
11. El-Kashif M.M.L., Fathy A.M., Elsaba H.A.H.F. Evaluation of maternal and neonatal outcomes in the case of preterm premature rupture of membranes and their relationship to prenatal maternal indicators: Across-sectional descriptive study //Journal of Nursing Education and Practice. 2020. T. 10. № . 6.

12. Lee Y.J. et al. Amniotic fluid index, single deepest pocket and transvaginal cervical length: Parameter of predictive delivery latency in preterm premature rupture of membranes //Taiwanese Journal of Obstetrics and Gynecology. 2018. Vol. 57. № . 3. C. 374-378.

13. El Sokkary F.M., Nassef A., Zidan M.M. Prediction of latency interval of labour in preterm premature rupture of membranes by $2 \mathrm{D}$ ultrasound: Case control study //Evidence Based Women's Health Journal. 2020. Vol. 10. № . 1. C. 79-88.

14. Mubarak A.M. Transvaginal cervical length and amniotic fluid index: Can it predict delivery latency following preterm premature rupture of membrane? // Medical Journal of Babylon. 2018. T. 15. № . 1. C. 78-82

15. Дятлова Л.И., Чеснокова Н.П., Понукалина Е.В., Рогожина И.Е., Глухова Татьяна Николаевна Патогенетическое обоснование дополнительных объективных критериев возможности эффективной пролонгации беременности при дородовом излитии околоплодных вод // Медицинская иммунология. 2015. № 2. C.159-166

( ) Шубитидзе Нана Георгиевна ( nanashubitidze3@gmail.com ),

Густоварова Татьяна Алексеевна, Таборидзе Иамзе Ираклиевна ( iataboridze@yahoo.com ).

Журнал «Современная наука: актуальные проблемы теории и практики»

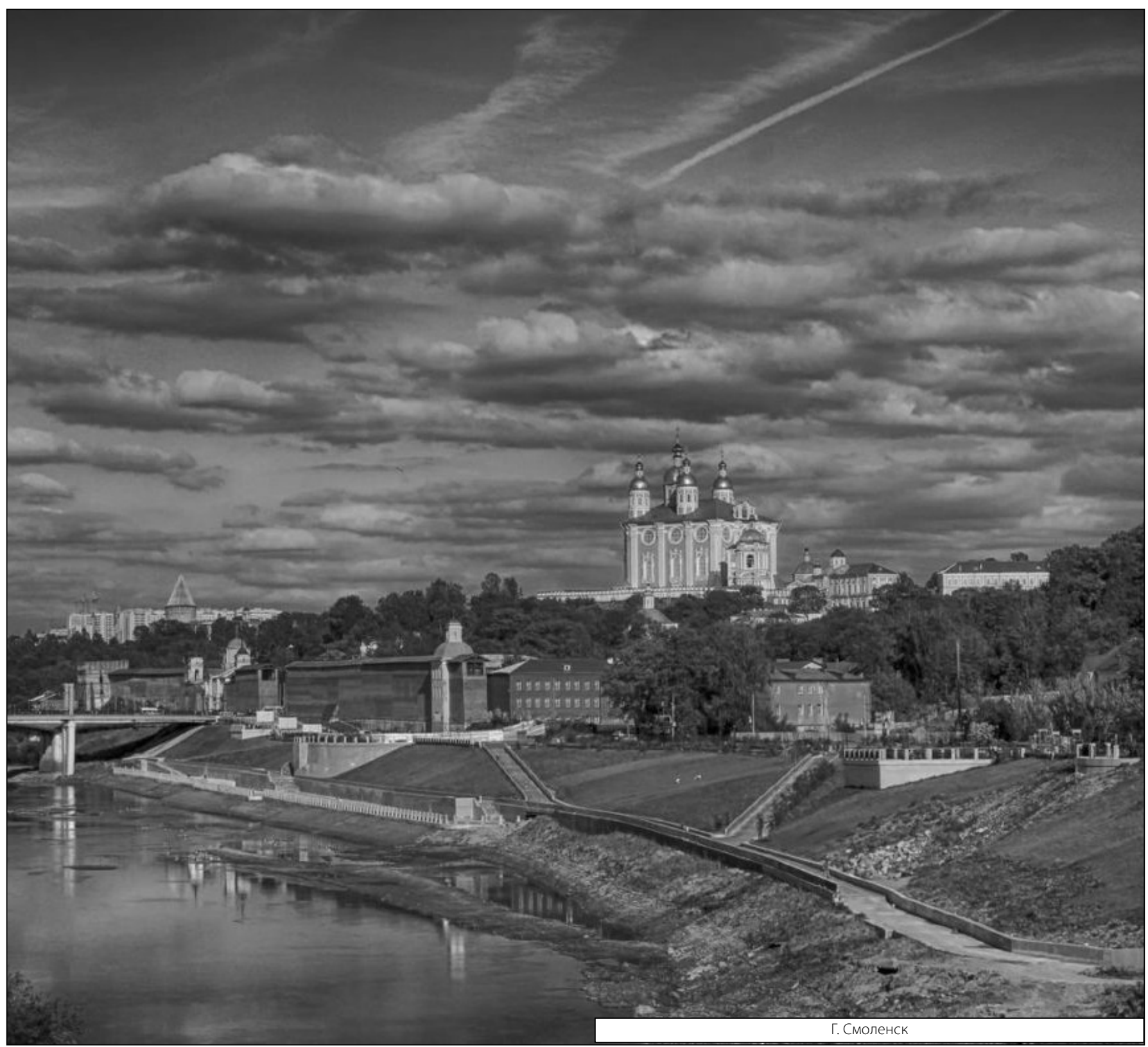

